\title{
Principal Approaches of Modern Psychology to Constructing Giftedness*
}

\author{
Marina Ivleva \\ Faculty of Humanities and Social Sciences \\ Department of Social Philosophy \\ Peoples' Friendship University of Russia (RUDN University) \\ 6 Miklukho-Maklaya Street, Moscow, 117198, Russia \\ E-mail: marinanonna@yandex.ru
}

\begin{abstract}
In the article, an attempt is made to identify the essential characteristics of the phenomenon of giftedness based on the analysis of existing approaches to the study of giftedness in contemporary psychology, the totality of which determines both the semantic structure of the concept of "giftedness" and its correlation with related concepts.
\end{abstract}

Keywords-Giftedness; terminological analysis; definition analysis; theoretical construct; essential characteristics

\section{INTRODUCTION}

Giftedness is a complex phenomenon, heterogeneous in its manifestations. A relevant way to delineate the boundaries of this phenomenon would be to review the existing numerous and diverse approaches of modern scientific psychology to the study of this phenomenon $[1,2]$. The fact that there is coexistence of such different approaches to the definition of giftedness is largely due to the multifaceted nature and complexity of the phenomenon in question.

In view of the above, at the present stage of the development of the psychological concept of giftedness, the most methodologically promising appears to be such a concept of giftedness as is characterized by openness, the absence of rigid values, and, in view of its ambiguity and difficult formalizability, an essential descriptiveness. In our opinion, these qualities are reflected in a definition developed by the team of authors of the "Working Concept of Giftedness of the Ministry of Education of the Russian Federation", according to which "giftedness means a systemic quality of the psyche that develops throughout life and that determines the possibility for a person to achieve higher (unusual, uncommon) results in one or several kinds of activity in comparison with other people" [3. P.4]

However, the above definition, while describing the important external characteristics of giftedness, does not reveal its true essence. The task of constructing a

\footnotetext{
This paper was financially supported by the Ministry of Education and Science of the Russian Federation on the program to improve the competitiveness of Peoples' Friendship University (RUDN University) among the world's leading research and education centers in the 2016-2020 (The Agreement number 02.A03.21.0008).
}

constructive definition of giftedness reflecting the essential characteristics of the phenomenon at hand remains unsolved.

\section{TERMINOLOGICAL AND DEFINITIONAL ANALYSIS OF GIFTEDNESS}

In terms of terminology, the phenomenon of giftedness in modern psychology is represented by a whole range of expressions. The most terminological diversity is observed in the English literature where the synonymous of the term "gifted" are such terms as talented, genius, endowed, exceptional, able, rapid learner, creative, bright, increasingly creative etc.

The term "giftedness" itself in the twentieth century replaced the earlier term "genius". But the term "giftedness" is often substituted for with such terms as "ability", "talent", "successful learner", "advancedness", "intelligence", etc. In the United States, a definition formulated in a report of the Department of Education to the US Congress was used for a long time. According to this definition, the following parameters of giftedness are distinguished: the functional or potential capabilities of a child in such areas as intellectual, academic, creative, artistic areas and in the area of communication or psychomotorics. Moreover, the presence or absence of these parameters is established by a professional [4].

This definition is sufficiently broad and gives considerable scope for researchers in terms of diagnostic procedures. At the same time, it does not lack shortcomings which, for example, were pointed out by J. Renzulli, and namely: the confusion of concepts of different levels (types of giftedness and areas of their manifestations), the lack of a motivational component. To replace this definition, J. Renzulli singled out other parameters, from the combination of which the phenomenon under investigation arises: intellectual abilities above the average level, creativity and perseverance [5]. However, this definition cannot be recognized as complete either since it does not establish what the combination of the listed characteristics should be, what the share and the role of each of them should be, and what the degree of their heritability and variability is. 
In general, there is an impression of a lack of strictly fixed terminology in foreign studies. Orientation on practical results of research is often realized at the expense of a rigorous theoretical justification. The terms employed are used without a clear division of their content for different contexts and without establishing a connection between them, which leads to contradictory and ambiguous interpretations of the concept of giftedness itself by foreign scientists.

In Russian psychology, the terminology spread can also be observed. "Gifted", "capable", "advanced", "talented", "smart", "versatile", "brilliant", "successful", "smart", "clever" - this is far from a complete list of synonyms used in psychological and psychological-and-educational literature. But on the whole, the Russian tradition of psychological science is characterized by a priority orientation toward theoretical comprehension of the phenomena under study. Hence a greater certainty in the conceptual field.

One of the first classical scientific definitions of giftedness was proposed by B. M. Teplov [6], who gave the definition of giftedness as a measure of a special combination of individual psychological features that directly determine the possibility of successful performance of an activity, the acquired opportunities for the successful performance of an activity of a person as a result of the development of abilities.

The key concepts of this definition are "individual psychological characteristics", "activity", "ability". Note that in the treatment of giftedness by B. M. Teplov there may be observed a certain duality, manifested in the absence of an unambiguously defined position regarding the nature of the phenomenon being determined. This duality is expressed in the disjunctive structure of the definition: giftedness is defined both as an innate and as an acquired characteristic.

The difference between abilities and giftedness, according to B. M. Teplov, is that if abilities are the result of development of in-born gifts in the process of the corresponding activity, then giftedness is a totality of these gifts, and, therefore, does not depend on their development.

According to B. M. Teplov, giftedness operates as a kind of primary cumulative effect of natural gifts, and the latter are considered as the initial given. Such an approach to the definition of giftedness can be characterized as psychological atomism, since it does not involve the study of the internal structure of the gifts and also does not involve the consideration of giftedness as a growing, developing and modifying mental education. Note that a similar position is taken by J. Gilford [7].

A significant contribution to the development of the concept of giftedness was made by the cultural-genetic method developed by L.S. Vygotsky. L. S. Vygotsky considers giftedness as a genetically conditioned component of abilities developing in the corresponding activity or degrading in the absence of such activity. Giftedness, as understood by L. S. Vygotsky, is viewed as a potency inherent in a person which can be revealed and actualized only in the process of learning activity under the guidance of a competent teacher [8].

Later definitions of giftedness reflected changes in the theoretical and methodological positions of the researchers of this problem. For example, V. D. Shadrikov defines giftedness as an integral manifestation of creative abilities for the purposes of concrete activity [9]. And this means that giftedness is a developing quality.

Wide currency is enjoyed by the concept of giftedness by A. M. Matushkin who considers giftedness to be a general psychological prerequisite for creative development [10]. And in this definition, the following structural components (factors) of giftedness are distinguished: the dominant role of cognitive motivation; creative research activity manifested in the discovery of new facts, in setting and solving problems; the possibility of achieving original solutions; possibility of prediction and anticipation; the ability to create ideal standards that provide high aesthetic, moral, intellectual estimates.

The comparison of this treatment of giftedness with the treatment of giftedness by B. M. Teplov demonstrates a fundamentally different ontological approach to the phenomenon under study, and namely, giftedness does not appear as a set of atomic innate properties of an individual but as a dynamic system of qualities, each of which, in turn, has a complex structure and is the result of development implying the obligatory presence of a social environment and an activity context.

A departure from the atomistic treatment of giftedness as the primary cumulative effect of innate in-born gifts had led to the fact that psychologists began to correlate giftedness not so much with psychological in-born gifts as with abilities as a more complex, derivative phenomenon.

It is interesting to note that the majority of foreign psychologists (in particular, A. Binet, E. Trondike, G. Revesh and others) associate creative abilities with giftedness. At the same time, most foreign scientists believe that creative abilities (and hence, giftedness) are an innate phenomenon while school abilities are largely the result of work and learning. This shows the relationship between giftedness and creativity: giftedness differs by having an innate character, and the natural condition for the manifestation of giftedness is creativity, creative activity.

In Russian psychology, there is a widely held thesis about the decisive importance of social factors in the development of natural inclinations. Congenital and acquired as the two components of abilities stand together, and are indistinguishable. But the fundamental solution to this problem is in that that the makings of abilities are inherent some anatomical and physiological features of the brain and nervous system with which a person comes into being. As S. L. Rubinstein noted [11], the abilities are not predetermined but they cannot just be supplanted from the outside. In individuals there must be preconditions, internal conditions for the development of abilities. It is these internal conditions that apparently should constitute the ontological basis of 
giftedness which is located in the continuum between inborn gifts or inclinations and abilities.

What has been said clarifies in many respects the relationship between the concepts of "giftedness", "ability", "makings", "creativity". Being ontologically conjugated with the in-born makings or gifts, giftedness cannot display itself other than in abilities, the full realization of which occurs in creativity.

Analysis of the main approaches by foreign and domestic Russian representatives of modern psychology to the phenomenon of giftedness [in more detail, see: 12], allows us to conclude that these approaches reflect different aspects of the phenomenon under study and therefore give different answers to questions about its nature and structure. On this basis, the following groups of approaches can be provisionally distinguished:

- first, the approaches which, in our opinion, it is fair to call "atomizing". These approaches include, in particular, the approaches of such psychologists as J. Guilford, B. V. Teplov and others. For these approaches, characteristic is the consideration of giftedness as the primary (simple) cumulative effect of the in-born gifts or inclinations which in turn are interpreted as an elementary (atomic) natural given. And in so doing, giftedness itself can be understood in a "realistic" manner as an ontological phenomenon (as, for example, in the early works of B. M. Teplov) but can also act as theoretical fiction, since the concepts of makings of abilities and abilities themselves are quite sufficient to explain the development of special abilities (the late works of B. M. Teplov);

- second, approaches which we will conditionally call "potentialist" (S. L. Vygotsky, Yu. D. Babaeva, etc.). Within these approaches, giftedness is seen as a genetically determined component of abilities developing in the corresponding activity, or degrading in its absence, that is, as a potential that can be actualized under certain conditions that are not dependent on the subject themselves;

- third, the so-called "transcendentalist" approaches (A. A. Melik-Pashayev, V. I. Panov, etc.). Representatives of these approaches see the essence of giftedness in the creative nature of the psyche which is actualized in interaction with the environment. At the same time, the environment, in turn, is actively formed by a subject who aspires to go beyond the bounds of his life, to overcome the limitations of his experience. These approaches are characterized by the recognition of an external, transcendental source of giftedness, understood as a sort of spiritual potential.

\section{IDENTIFICATION OF THE ESSENTIAL CHARACTERISTICS OF GIFTEDNESS}

The treatment of giftedness as an objectively existing phenomenon allows us to note its versatility, the variety of its manifestations This explains not only the complexity of the conceptualization of this phenomenon, but also the inability to cover all its manifestations in one, sufficiently complete and at the same time consistent, definition. The first step on the way to solving this problem should be to identify the essential characteristics of the phenomenon in question. At the same time, one must proceed from the fact of the objective existence of giftedness as, if not psychological, then at least a socio-cultural phenomenon. If we consider giftedness in the objectivist vein as a purely psychic phenomenon, then the question of why the concept of giftedness falls into the field of view of psychologists only in the twentieth century does not find an answer. If we consider it as a theoretical construct, then the questions about the conditions under which the psychological science develops this theoretical construct, on which philosophical (ontological, epistemological, anthropological, axiological) and empirical premises it is based on, acquire a completely legitimate character.

V. A. Smirnov identifies two types of objects used in scientific theories: empirical and theoretical objects [13]. Empirical objects are none other than abstractions, theoretical objects are idealizations used in the course of theoretical reconstruction of reality. In the light of this position, giftedness is an abstraction, that is, an empirical object.

The general state of research into giftedness in modern psychology points to the need for a profound interpretation of the philosophical grounds for studying this empirical object. In the meantime, the very ways in which psychologists construct giftedness as an abstract object turn out to be fundamentally different. Thus, some scientists (including those from the school of B. M. Teplov) set as their task a theoretical explanation of the nature of giftedness as a structure of properties transformed into differential structures in the process of development. The efforts of others focus more on describing certain qualities (emotional, communicative, characterological, motivational and other) of gifted people than on resolving the question of the essence of giftedness, its sources and the driving forces of development (Freehill; Freeman; Taylor). Still others consider giftedness as a complex quality not reducible to intellectual or personal characteristics but rather integrating factors of different nature (Bogoyavlenskaya, D. B., Matyushkin, A. M., Tannenbaum; Renzulli).

A review of the approaches of modern psychology to the construction of giftedness makes it possible to single out the basic semantic parameters of this theoretical construct, to which the essential characteristics of the corresponding empirical object (the phenomenon of giftedness) correspond. Note that, within the framework of different approaches, these parameters can take on different values, however these parameters themselves should be preserved in any approach to the study of giftedness, since their totality defines both the semantic structure of the concept of "giftedness" and its correlation with related concepts. Let us enumerate these semantic parameters: 
- The relationship between the inherent and acquired, hereditary and environmental factors in the development of giftedness determines its correlation with the concepts of in-born gifts and abilities. In the structure of giftedness, we should note the important role of anatomical and physiological instincts and sensory-perceptual components characterized by increased sensitivity.

- Connection with the formation of a person as an individual and subject of activity. Giftedness is an active expression of subjectivity, because it is both a prerequisite for the further development of abilities and in-born gifts, and the result of their development, and can also manifest itself only in development.

- Subject-activity specialization of giftedness as a result of close association with activities as the original phenomenon which determines its development and function in a variety of forms and, as a consequence, which is expressed in various kinds of giftedness (artistic, technical, mathematical, etc.).

- The relationship of giftedness with the concept of "intellect" is due to a special role in the structure of giftedness of intellectual abilities as its universal characteristic. Studies have confirmed that the achievement of a good result is possible thanks to the initial, structural conditions, both intellectual and mental capabilities, that allow you to assess new situations and solve new problems; they are characterized by the understanding of the nature of problems and problematic situations; generating fast solutions, assessments and forecasts.

- The next universal characteristic of giftedness is a creative component which is manifested through the ingenuity, resourcefulness, multiplicity of solutions; connection with self-development, self-expression, self-actualization.

- Another essential characteristic of giftedness serving as a necessary condition of its development is a motivational component expressed in the domination of interests and motives over the corresponding activity; emotional immersion in the work, the desire to deal with it.

- Giftedness is manifested also through a high level of production of new images, fantasy, imagination which significantly increases the efficiency of activity, mainly, innovation.

- Great importance in the structure of giftedness is allocated to emotional volitional structures predetermining long dominant orientations, emotional immersion in activity; maintaining artificially such activity; pleasure and aesthetic satisfaction both from the very process of activity and from its results; will to achieve success, perfectionism.

- Manifestations of giftedness that are represented at all levels of human mental organization are diverse and complex. Giftedness itself can be regarded as a prerequisite for the formation of such macro characteristics of a person as personality and individuality which reflect his social nature and both as an individual and the subject in which their natural biological entity is reflected.

- Finally, another important characteristic of giftedness is its important role in the formation of both integrating, combining relations of a human being with the biosocial environment surrounding him (both as an individual and a personality), and also in the formation of differentiators that separate him from the natural and social environment relations that characterize the person as an individual and the subject of activity.

The above-proposed list of the essential characteristics of giftedness selected by us is not final and can be expanded to include its other structures. It is necessary to emphasize the unused heuristic potential of this list in the understanding of the phenomenon under analysis as the characteristics indicated in this paper can act as independent criteria for the classification and evaluation of the many and varied theories of giftedness. As is known, at the present stage of development of psychological science, there are many different theoretical models of giftedness but, in most of them, virtually all the elements of the semantic space concept of "giftedness" corresponding to the essential characteristics specified above are represented in one form or another.

\section{CONCLUSION}

The reason for the variety of approaches to the study of giftedness in psychology is not so much in the versatility of the studied phenomenon but in the difference of the cognitive systems of researchers, their ways of thinking which are based on different philosophical foundations [14]. Scientific approaches based on different philosophical basis reflecting different aspects of the phenomenon of giftedness (different manifestations of its essential characteristics), and give different answers to questions about the nature and structure of giftedness. We have identified the following groups of approaches.

I. Approaches based on the interpretation of giftedness as a natural given, ontological phenomenon which represents the sum total of in-born gifts. On this basis, there is an allocation of inclinations and differentiation of abilities, types of giftedness. These approaches rely on Democritus', line of developing philosophical substantiations for these approaches (J. Guildford, B. M.Teplov and others).

II. Approaches where giftedness is seen as a genetically determined component of abilities developing in a corresponding activity, or degrading in its absence, that is, as a potential that can be actualized under certain conditions that are not dependent on the subjects themselves. Representatives of these approaches continuing the crossparadigm line of Aristotle with his idea of actualizing potential abilities are S. L. Vygotsky, Yu. D. Babaeva and others. 
III. So-called "transcendentalist" approaches (A. A. Melik-Pashayev, V. I. Panov and others) continuing the "Platonic" line of developing philosophical substantiations. As the defining condition of formation and development of giftedness, the authors of these approaches consider the creative nature of the psyche and giftedness which is actualized in the interaction with the environment and, unlike other approaches, they admit of the ability of a subject to be actively forming the environment.

Thus, having examined the main approaches of modern psychology to the definition of the concept of giftedness, we found that this concept reflects the totality of ideas developed by modern psychology about the phenomenon of giftedness and implicit, theoretically unreflected, understanding of its defining characteristics.

Based on analysis of the use of the concept of "giftedness" and the related concepts we have identified the essential characteristics of the phenomenon of giftedness, the combination of which defines both a semantic structure of the concept of "giftedness" and its relation with the related concepts.

The reason for the variety of approaches to the study of giftedness in psychology is both the multitude of the manifestations of the phenomenon of giftedness and differences in cognitive concepts of researchers, ontological presuppositions implicitly accepted by them, gnosiological and anthropological assumptions [15], and value concepts, at the base of which, in turn, is the difference in the philosophical substantiations of these approaches.

\section{REFERENCES}

[1] Bagramyants M.L. Psychology of giftedness: theory, experiment, practice: a manual. M., 2008.- 150 p.

[2] Bagramyants M.L. Endowment as a Theoretical and Practical Problem of Psychology: A Scientific and Practical Handbook. M., 2003.- $142 \mathrm{p}$.

[3] Giftedness: Working concept / Ed. V.D. Shadrikov. M., 1998.

[4] Marland S. Education of the gifted \& talented : Report to the Congress of the United States by the Commissioner of Education. Washington DC: US Office of Education. 1972.

[5] Renzulli J. S. The three-ring conception of giftedness: A developmental model for creative productivity// Sternberg R. I., Davidson J. E. (eds.). Conceptions of giftedness. Cambridge: Cambr. Univ. Press, 1986. P. 53-92.

[6] Teplov B. M. Abilities and giftedness // Selected Works. M, 1985. V.1. P. 15-41.

[7] Guilford J. P. The nature of human intelligence. New York: McGrowHill. 1967.

[8] Vygotsky L.S. Psychology of art. Ed. M.G. Yaroshevsky. M., 1987.

[9] Shadrikov V.D. Activity and abilities. M: The Logos. 1994.

[10] Matyushkin A. M. The concept of creative giftedness / / Questions of psychology, 1989, № 6. P. 29-34.

[11] Rubinstein S.L. Problem of abilities and questions of psychological theory // Problems of general psychology. M., 1972. P. 220-235.

[12] Ivleva M.L. Scientific stage of development of the psychological concept of giftedness: trends, trends, approaches: monograph / M.I. Ivleva. - M .: MSTU "MAMI", 2012. - 195 p.
[13] Smirnov V.A. Levels of knowledge and stages of the process of knowledge / / Problems of the logic of scientific knowledge. M., 1964. - P. 23-52.

[14] Ivleva M.L., Bagramyants N.L., Ivlev V.Y., Oseledchik M.B. Methodological Principles of the Study of the Philosophical Foundations of Psychological Conceptions of Giftedness//Proceedings of the 2016 3rd International Conference on Education, Language, Art and Inter-cultural Communication (ICELAIC 2016). Advances in Social Science, Education and Humanities Research. Paris: Atlantis Press, 2017. Volume 40. P. 4852.

[15] Chistyakova O.V. Russian Religious Philosophy as the Basis for State Identity // Journal of Eurasian Research. 2003. Volume 2. № 1. - P. 13-17. 